\title{
Glomerulosclerosis Induced by In Vivo Transfection of Transforming Growth Factor- $\beta$ or Platelet-derived Growth Factor Gene into the Rat Kidney
}

\author{
Yoshitaka Isaka, Yoshihiro Fujiwara, Naohiko Ueda, Yasufumi Kaneda, ${ }^{\star}$ Takenobu Kamada, and Enyu Imai \\ First Department of Medicine, Osaka University Medical School, and *Institute for Molecular and Cellular Biology, Osaka University, \\ Suita, Osaka 565, Japan
}

\begin{abstract}
Glomerulosclerosis, a final common lesion of various glomerular diseases, is characterized by mesangial cell proliferation and extracellular matrix (ECM) expansion. TGF- $\beta$ and PDGF are known to play a critical role in the regulation of ECM metabolism and mesenchymal cell proliferation, respectively. However, there is little evidence to demonstrate the direct role of each of these growth factors in the pathogenesis of glomerulosclerosis. Using an in vivo transfection technique, we could realize the selective overexpression of single growth factor in the kidney. The introduction of either TGF- $\beta$ or PDGF-B gene alone into the kidney induced glomerulosclerosis, although the patterns of action of these growth factors were different; TGF- $\beta$ affected ECM accumulation rather than cell proliferation and PDGF affected the latter rather than the former. (J. Clin. Invest. 1993. 92:2597-2601.) Key words: hemagglutinating virus of Japan • liposome • mesangium • proliferation • extracellular matrix $\bullet$ glomerulonephritis
\end{abstract}

\section{Introduction}

Glomerulosclerosis is considered to be the final common pathway leading to the progressive loss of renal function in various types of primary glomerulonephritis, diabetic nephropathy, and lupus nephritis. A variety of in vitro studies have suggested that growth factors, especially TGF- $\beta(1,2)$ and PDGF $(3-5)$, contribute to the pathophysiological process in the development of glomerulosclerosis characterized by mesangial cell proliferation and extracellular matrix (ECM) ${ }^{1}$ expansion. Furthermore, the pathogenetic involvement of these growth factors in experimental glomerulonephritis has been shown in vivo, if not directly: Both factors were highly expressed in diseased glomeruli (6-8) and antiserum against TGF- $\beta$ (9) or PDGF-B (10) could suppress the disease progression in anti-Thy 1 experimental glomerulonephritis. Nevertheless, it still remains obscure whether TGF- $\beta$ or PDGF plays a direct role in vivo in the

Address correspondence to Dr. Enyu Imai, First Department of Medicine, Osaka University Medical School, 2-2, Yamada-Oka, Suita-city, Osaka 565, Japan.

Received for publication 18 May 1993 and in revised form 9 July 1993.

1. Abbreviations used in this paper: CAT, chloramphenicol acetyltransferase; ECM, extracellular matrix; HMG-1, high mobility group 1; HVJ, hemagglutinating virus of Japan; PCNA, proliferating cell nuclear antigen.

\footnotetext{
J. Clin. Invest.

(c) The American Society for Clinical Investigation, Inc.

$0021-9738 / 93 / 12 / 2597 / 05 \quad \$ 2.00$

Volume 92, December 1993, 2597-2601
}

pathogenesis of glomerular injury. To investigate the independent role of each factor in experimental animals, a transgenic animal model may be the most plausible candidate (11). However, the expression of a factor that targets the kidney is not possible at present, and indirect influences of the systemically overexpressed factor are probably inevitable. The objective of this study was to show that selective overexpression of TGF- $\beta$ or PDGF in rat glomeruli mediates glomerulosclerosis.

\section{Methods}

Construction of expression vectors. We constructed TGF- $\beta 1$ and PDGF-B expression vectors designated pAct-TGF $\beta$ and pAct-PDGF, respectively. The pAct-CAT plasmid, originally constructed by N. Davidson, contains bacterial chloramphenicol acetyltransferase (CAT) gene with the chicken $\beta$ actin promoter gene, the SV40 early promoter on the $5^{\prime}$ end, and SV40 splice and polyA sequences on the $3^{\prime}$ end (12). pAct-TGF $\beta 1$ and pAct-PDGF were constructed by exchanging the coding region of CAT gene (HindIII/HpaI fragment of pAct-CAT) from pAct-CAT with the EcoRI fragment containing the complete coding region of TGF $\beta 1$ cDNA from phTGF-2 (13) and the BamHI fragment containing complete coding region of PDGF-B cDNA from pSM-1 (14), respectively. phTGF-2 and pSM-1 were supplied by American Type Culture Collection Rockville, MD.

Introduction of Plasmid DNA into rat kidney. Plasmid DNA containing cDNA for TGF $\beta 1$, PDGF-B, or CAT was introduced into rat kidney via left renal artery by the hemagglutinating virus of Japan (HVJ)-liposome method, which has been applied for the transient transfection in vivo. The procedure of the preparation of HVJ-liposomes was as described previously $(15,16)$. Briefly, dried lipid mixture (phosphatidylserine, phosphatidylcholine, and cholesterol), and plasmid DNA, previously incubated with nuclear protein, high mobility group 1 (HMG-1), were shaken vigorously and sonicated to form liposomes. The liposomes were incubated with inactivated $\mathrm{HVJ}$ and fused into HVJ-liposomes. The HMG-1 accelerates migration of a foreign DNA into the nuclei when co-introduced with plasmid DNA, while HVJ protein facilitates the fusing of the liposome with the plasma membrane. 8-wk-old Sprague-Dawley rats (Japan SLG, Inc., Hamamatsu, Japan ) were anesthetized by intraperitoneal injection of pentobarbital $(50 \mathrm{mg} / \mathrm{kg})$, and a catheter was inserted into the left renal artery. $0.5 \mathrm{ml}$ of $\mathrm{HVJ}$-liposome suspension (2-10 $\mu \mathrm{g}$ of encapsulated DNA in BSS [ $140 \mathrm{mM} \mathrm{NaCl}, 5.4 \mathrm{mM} \mathrm{KCl}, 10 \mathrm{mM}$ Tris- $\mathrm{HCl}, \mathrm{pH}$ 7.6.] with $1 \mathrm{mM} \mathrm{CaCl}$ ) was injected through the catheter after flushing with $1 \mathrm{ml}$ of $0.9 \% \mathrm{NaCl}$ solution.

Histological analysis. Animals were sacrificed under sodium pentobarbital ( $50 \mathrm{mg} / \mathrm{kg}$, i.p.) anesthesia on day 3,5, and 7 after the introduction and both kidneys were fixed for light micrography and immunofluorescence. At least six rats were examined for each expression vector in each time point. For immunohistochemistry, the kidneys were fixed in buffered formaldehyde and 5- $\mu \mathrm{m}$-thick cryostat sections were blocked with 5\% normal sheep serum in PBS for $30 \mathrm{~min}$, incubated with first antibody for $1 \mathrm{~h}$, and incubated with second antibody (fluorescein-conjugated sheep antibody against rabbit IgG; Silenus Laboratory, Hawthorn, Victoria, Australia) for $\mathbf{3 0} \mathrm{min}$ at room temperature. To confirm the expression of the introduced cDNAs, rabbit antihuman TGF $\beta 1$ and rabbit anti-human PDGF-B (both from King Brewing Co., LTD., Kakogawa, Japan) were used as first antibodies. These antibodies crossreact to rat TGF- $\beta 1$ and PDGF-B, respectively. 
To estimate the transfection efficiency, rabbit anti-CAT (5Prime $\rightarrow$ 3Prime, Inc., Boulder, $\mathrm{CO}$ ) were used as first antibodies, and CATpositive glomeruli were counted. To examine the proliferating cells, mouse antibody to proliferating cell nuclear antigen (PCNA; Coulter Clone, Hialeah, FL), which is a cell proliferation marker, and ED1 (Serotec LTD, Oxford, UK), mouse antibody to rat monocyte and macrophages, were used as first antibodies. For light microscopy, tissues were fixed in neutral formalin and enbedded in paraffin, and $2-\mu \mathrm{m}$ sections were stained with periodic acid-Schiff. To quantitate mesangial matrix expansion and glomerular cell counts, all sections were read by an observer unaware of the experimental protocol. 30 glomeruli (80-100 $\mu \mathrm{m}$ in diameter) were selected at random in sections from rats on day 3,5 , and 7 after introduction of control CAT, TGF $\beta 1$, or PDGF gene. The degree of glomerular matrix expansion was determined by Raij's method (17). For the qualitative analysis of the accumulated matrix, rabbit antibodies to collagen type I, III, IV, which were gifts from Dr. Ohshima (Department of Pathology, Wakayama Medical College, Wakayama, Japan ) were used as first antibodies of the immunofluorescence.

\section{Results}

TGF- $\beta 1$ or PDGF-B was detected immunohistochemically (15) in the glomeruli and interlobular arteries $3 \mathrm{~d}$ after the introduction of TGF- $\beta 1$ or PDGF-B gene, respectively (Fig. $1)$. The transfection efficiency into the glomerulus was estimated as $\sim 35 \%$, because CAT protein was detected in 30 to $40 \%$ of glomeruli in all of rats introduced CAT gene, and TGF$\beta$ and PDGF were overexpressed in glomeruli in similar percentage. The expression vectors could be introduced selectively into the left kidney since overexpressed proteins were not found in the right kidney. Either one of TGF- $\beta 1$ and PDGF-B was unseen after the introduction of the other gene. Neither TGF- $\beta 1$ nor PDGF-B was expressed in the kidney after CAT gene was introduced. This implies that human TGF- $\beta 1$ or PDGF-B was highly expressed in the glomeruli as a single autocrine and/or paracrine factor. We evaluated histological disease activity on 3, 5, and $7 \mathrm{~d}$ after gene introduction. A pathological alteration of the glomeruli was present in all of the rats transfected with either TGF- $\beta 1$ or PDGF-B gene.

Fig. 2 shows representative photomicrographs of glomeruli from transfected rats. In the TGF- $\beta 1$ gene-transfected rats, an extensive ECM expansion with a moderate mesangial cell proliferation was observed. In contrast, the major alteration in the PDGF-B gene transfected rats was a striking increase in cellularity with an ECM expansion. It is worthy of note that the conspicuous lobular architecture of the tufts, which sometimes leads to the formation of prominent nodules, was shown in this group.

The quantitated data on glomerular ECM expansion and mesangial cell proliferation are summarized in Fig. 3. Glomerular cell counts were increased to $115 \%$ and $145 \%$ of the control level (determined in the experiment using CAT gene) by TGF- $\beta 1$ and PDGF-B, respectively. No proliferative change was seen in glomeruli of right kidneys of TGF- $\beta$ - or PDGFtransfected rats. To confirm the mesangial cell proliferation, the left kidneys were examined immunohistochemically with anti-PCNA and anti-ED1 antibodies. The PCNA-positive cells were significantly increased in the glomeruli from PDGF or TGF- $\beta$ introduced rats, while ED1-positive cell number was unchanged. Polymorphonuclear cells were not infiltrated in the transfected kidney. These results suggest that the glomerular hypercellularity seems to result from the resident mesangial cells.
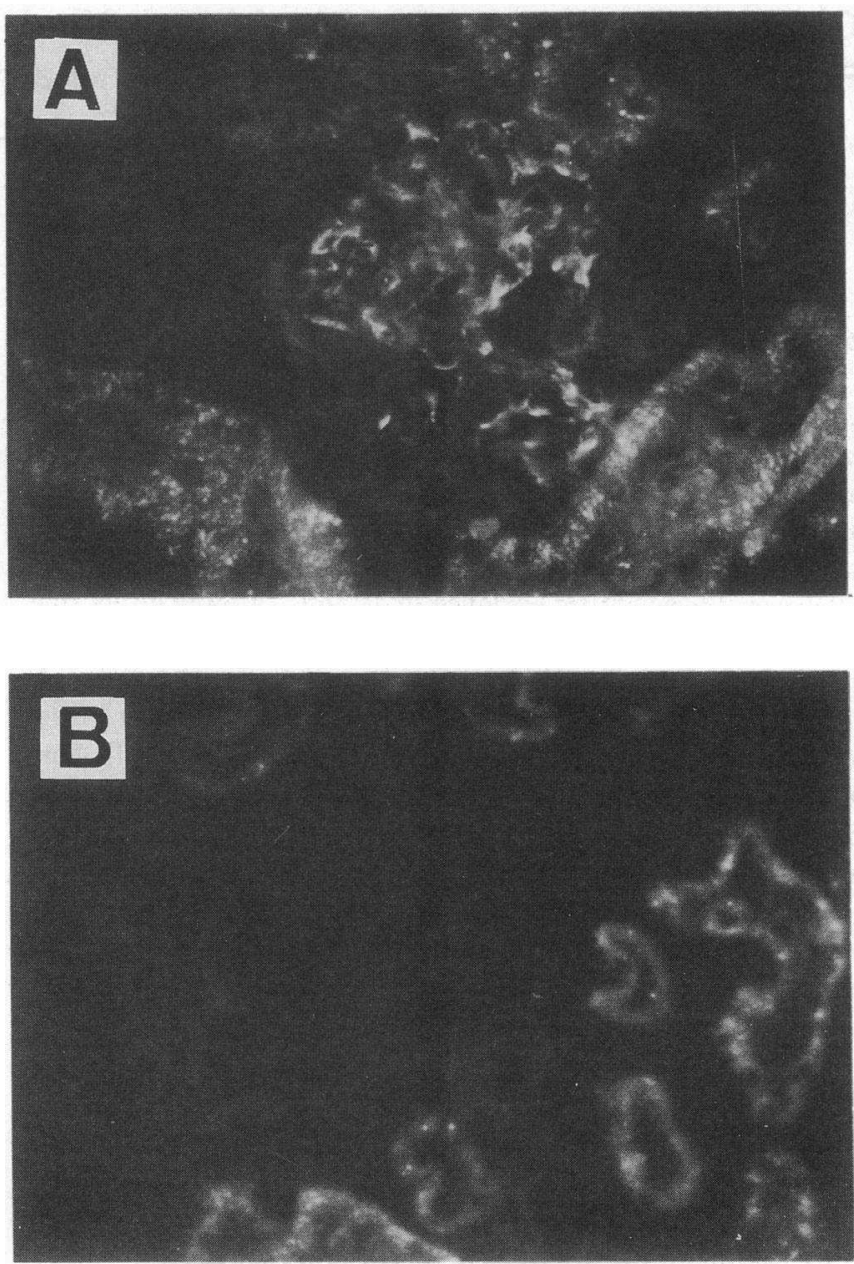

Figure 1. Immunofluorescence micrographs of glomeruli from transfected rats stained with anti-TGF $\beta 1$ antibody. The stain for TGF $\beta 1$ $3 \mathrm{~d}$ after introduction of TGF $\beta 1$ gene $(A)$ was striking, compared with that observed in the control experiment using CAT gene $(B)$. Renal tubules were artifactually stained. Original $\times 400$.

The glomerular matrix indices (17) determined for TGF$\beta 1$, PDGF-B, and CAT on day 5 were $46.4 \pm 18.4,20.8 \pm 18.4$, and 0 , respectively. The introduction of TGF $\beta$ or PDGF gene into the left kidney did not affect the matrix index of the contralateral right kidney. Apparent tubular lesion was not observed in the rat kidney introduced exogeneous TGF- $\beta$ or PDGF-B gene. There is a possibility to underestimate the matrix index and glomerular cell counts in the PDGF-B or TGF- $\beta$ gene transfected kidney, because quantitative analysis was performed by randomly selected 30 glomeruli, $30-40 \%$ of which were effectively transfected.

The qualitative analysis of the ECM accumulated in the sclerotic lesion using several antibodies to collagens showed that TGF- $\beta$ increased the contents of type I and type III collagens mainly in the mesangial area and appeared to produce a slight increase in type IV collagen, whereas the introduction of CAT had virtually no effects on collagen contents (Fig. 4).

Neither serum creatinine nor urea nitrogen was increased in all transfected rats. Pathological proteinuria was present in both TGF- $\beta$ gene- and PDGF-B gene-transfected rats, while pathological proteinuria was absent in the CAT gene-transfected rats. 

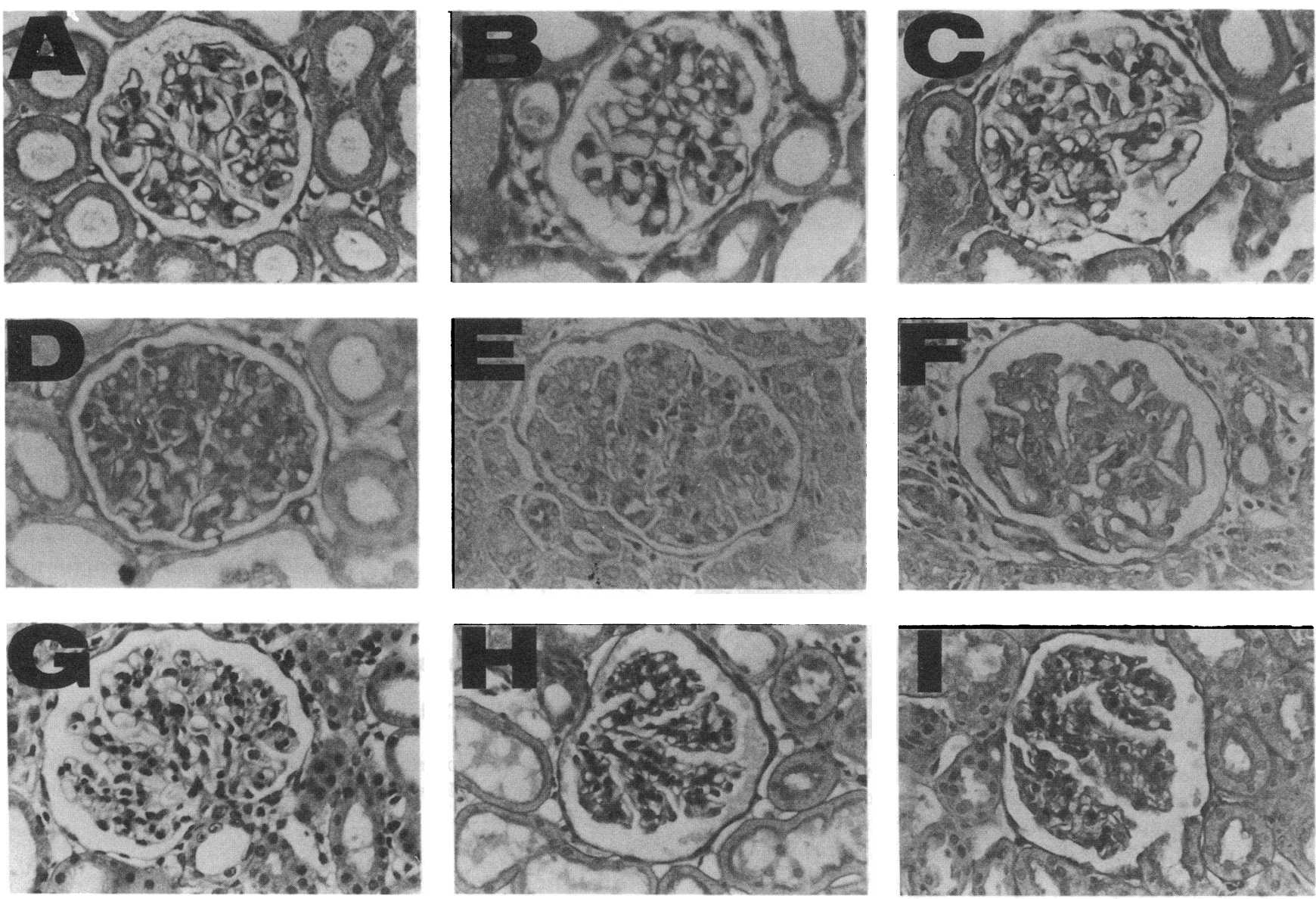

Figure 2. Histological changes of glomeruli from transfected rats. The micrographs show periodic acid-Schiff stains of glomeruli. $A-C$, from a control rat on day $3(A), 5(B)$, and $7(C) ; D-F$, from a TGF $\beta 1$ gene-transfected rat on day $3(D), 5(E)$, and $7(F) ; G-I$, from a PDGF-B gene-transfected rat on day $3(G), 5(H)$, and $7(I)$. A striking increase in ECM is seen in $D$. ECM is much more expanded in $E$ and $F$ than in $D$. Glomerular cells are increased in number in $G$ and they are accentuated as a lobular formation in $H$ and $I$. Original $\times 400$.

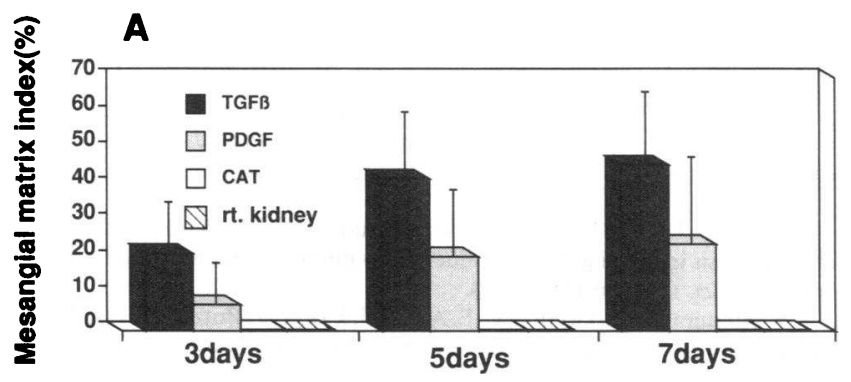

B

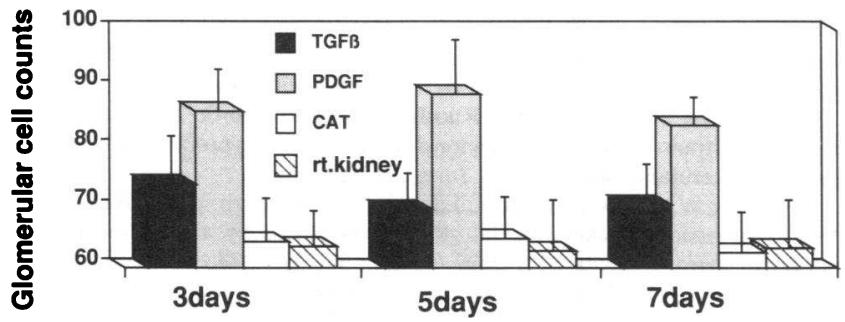

Figure 3. Quantitation of pathological changes. CAT; TGF $\beta 1$, or PDGF gene was introduced into the left kidney, and the severity of glomerular damage was evaluated on day 3,5 , and 7 by quantitating the ECM accumulation $(A)$ and glomerular cell count $(B)$. The right kidney of TGF- $\beta$ transfected rat was also calculated as control. The kidney sections were examined in four rats at each time point.

\section{Discussion}

The hallmark of the progressive glomerular damage is sclerosis. Sclerotic alterations in the glomeruli are believed to develop very slowly in the course of chronic glomerulonephritis. Immunological injury, lasting glomerular hypertension, and/or precedent glomerular hypertrophy are supposed to be triggers leading to eventual glomerulosclerosis. Surprisingly, in this study the pathological changes of the glomerulus took place within a week after transfection without a drastic precedent event like mesangiolysis in anti-Thyl glomerulonephritis. Here we propose a hypothesis that TGF- $\beta$ and PDGF play a primary role in the development of glomerulosclerosis; whatever triggers may increase glomerular TGF- $\beta$ and/or PDGF production, overexpressed TGF- $\beta$ and PDGF appear to accomplish the sclerotic change in the glomerulus in a short period even in the absence of abnormal physical force or immunological insults.

In this study the prominent change induced by TGF- $\beta 1$ was ECM expansion and that induced by PDGF-B was cell proliferation. There remains a possibility that PDGF may stimulate mesangial cells to release autocrine TGF- $\beta$ and that TGF- $\beta$ may also induce PDGF. However, TGF- $\beta$ was not detected immunohistochemically in the kidney from the transfected PDGF gene and vice versa. Thus, it is likely that the overex- 

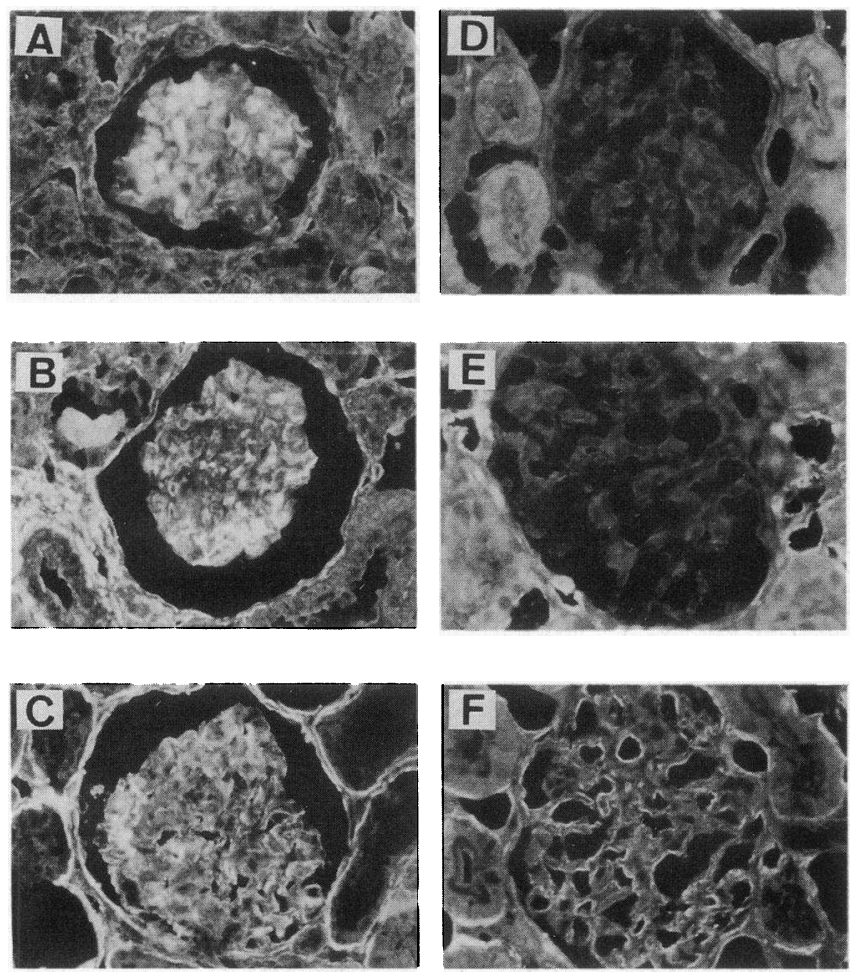

Figure 4. Immunofluorescence micrographs of glomeruli from transfected rats stained with anti-collagen type I $(A$ and $D)$, III ( $B$ and $E)$, IV $(C$ and $F)$ antibody. The stain for anti-collagen type I and III $3 \mathrm{~d}$ after introduction of TGF $\beta 1$ gene $(A$ and $B$ ) was striking, compared with that observed in the control experiment using CAT gene ( $D$ and $E$ ). The stain for anti-collagen type IV $(C)$ was slightly increased compared with that in the control study $(F)$. Original $\times 400$.

pressed factor may play a principal role in the development of the particular lesion, and that the behaviors of overexpressed TGF- $\beta$ and PDGF are different in in vivo milieu.

TGF- $\beta$ is known to enhance the synthesis of proteoglycans but not to substantially affect the content of type I, type III, or type IV collagen in cultured mesangial cells $(18,19)$. In cultured glomerular epithelial cells exposed to TGF- $\beta$ the secretion of proteoglycans and type IV collagen was strikingly increased, but neither type I nor type III collagen was produced (19). In our experimental model, TGF- $\beta$ did alter cell staining for type I and III collagens and appeared to produce a slight increase in type IV collagen. The normal glomerular mesangium contains only basement-membrane (type IV and V) collagens (20). Our results, however, seem to suggest that TGF- $\beta$ induces glomerular cells to produce interstitial (type I and III) collagens as well as basement-membrane collagens in vivo. These changes resemble the pathological changes of the glomeruli usually seen in patients with glomerulosclerosis (21).

TGF- $\beta 1$ has been reported to exert a bifunctional effect on mesangial cell growth in vitro (20); a low concentration promotes cell proliferation and a high concentration suppresses it. In the meantime, an elevated local expression of TGF- $\beta 1$ induced mesangial cell proliferation in the present in vivo experiment. The dual property of the growth factor may be dependent on the cellular milieu and the growth-promoting function may be preponderant in vivo.

The elevated expression of PDGF-B in vivo caused a proliferative change with a striking increase in cellularity and a rela- tively weak ECM accumulation. Up-regulation of the PDGF receptor may be a prerequisite to mesangial cell proliferation induced by overexpressed PDGF. The PDGF receptor $\beta$ subunit expression is known to be up-regulated in the experimental Thy-1 glomerulonephritis model (7). PDGF receptor $\beta$ is reportedly up-regulated in response to PDGF-B in an in vitro system $(22,23)$. The transient up-regulation of PDGF receptor due to PDGF-B overexpression gave a basis for the postulate that there exists a positive feedback mechanism, which can explain, in part, the reason why overexpressed PDGF-B exerted a strong proliferating action in the glomeruli.

In the present in vivo murine study we could introduce the exogeneous gene selectively into the rat kidney via the renal artery. Furthermore, our method itself is considered harmless, because neither histological changes nor pathological proteinuria were recognized in the control animals which received CAT gene. This HVJ-liposome method permits efficient selective gene transfer into the kidney, neither exerting a cytotoxic action nor giving immunological stimulation, and it can be a useful tool for studying the action of each individual growth factor in the kidney in situ.

\section{Acknowledgments}

We thank Dr. Akira Ohshima for gifts of rabbit antibodies to collagen type I, III, and IV.

This work was supported by grants from the Japanese Ministry of Science, Culture and Education, and from the Osaka Kidney Foundation (OKF-93-0012).

\section{References}

1. Border, W. A., and E. Ruoslahti. 1992. Transforming growth factor- $\beta$ in disease: The dark side of tissue repair. J. Clin. Invest. 90:1-7.

2. MacKay, K., L. J. Striker, J. W. Sttauffer, T. Doi, L. Y. Agodoa, and G. E Striker. 1989. Transforming growth factor- $\beta$ : murine glomerular receptors and responses of isolated glomerular cells. J. Clin. Invest. 83:1160-1167.

3. Floege, J., M. W. Burns, C. E. Alpers, A. Yoshimura, P. Pritzl, K. Gordon, R. A. Seifert, D. F. Bowen-Pope, W. G. Couser, and R. J. Johnson. 1992. Glomerular cell proliferation and PDGF expression precede glomerulosclerosis in the remnant kidney model. Kidney Int. 41:297-309.

4. Gesualdo, L., M. Pintzani, J. J. Floriano, M. O. Hassan, N. U. Nagy, F. P. Schena, S. N. Emancipator, and H. A. Abboud. 1991. Platelet-derived growth factor expression in mesangial proliferative glomerulonephritis. Lab. Invest 65:160-167

5. Silver, B. J., F. E. Jaffer, and H. E. Abboud. 1989. Platelet-derived growth factor synthesis in mesangial cells: Induction by multiple peptide mitogens. Proc. Natl. Acad. Sci. USA. 86:1056-1060.

6. Yoshimura, A., K. Gordon, C. E. Alpers, J. Floege, P. Pritzl, R. Ross, W. G. Couser, D. F. Bowen-Pope, and R. J. Johnson. 1991. Demonstration of PDGF B-chain mRNA in glomeruli in mesangial proliferative nephritis by in situ hybridization. Kidney Int. 40:470-476.

7. Iida, H., R. Seifert, C. E. Alpers, R. G. K. Gronwald, P. E. Phillips, P. Pritzl, K. Gordon, A. M. Gown, R. Ross, and D. F. Bowen-Pope. 1991. Platelet-derived growth factor (PDGF) and PDGF receptor are induced in mesangial proliferative nephritis in the rat. Proc. Natl. Acad. Sci. USA. 88:6560-6564.

8. Okuda, S., L. R. Languino, E. Ruoslahti, and W. A. Border. 1990. Elevated expression of transforming growth factor- $\beta$ and proteoglycan production in experimental glomerulonephritis. J. Clin. Invest. 86:453-462.

9. Border, W. A. S. Okuda, L. R. Languino, M. B. Sporn, and E. Ruoslahti. 1990. Suppression of experimental glomerulonephritis by antiserum against transforming growth factor $\beta 1$. Nature (Lond.). 346:371-374.

10. Johnson, R. J., Raines, E. W., Floege, J., Yoshimura, A., Pritzl, P., Alpers, C., and Ross, R. 1992. Inhibition of mesangial cell proliferation and matrix expansion in glomerulonephritis in the rat by antibody to platelet-derived growth factor. J. Exp. Med. 175:1413-1416.

11. Suematsu, S., T. Matsuda, K. Aozasa, S. Akira, N. Nakano, S. Ohno, J. Miyazaki, K. Yamamura, T. Hirano, and T. Kishimoto. 1989. IgGI plasmacytosis in interleukin 6 transgenic mice. Proc. Natl. Acad. Sci. USA. 86:7547-7551.

12. Fregien, N., and N. Davidson. 1986. Activating elements in the promoter region of the chicken $\beta$-actin gene. Gene. 48:1-11. 
13. Kasid, A., G. I. Bell, and E. P. Director. 1988. Effects of transforming growth factor- $\beta$ on human lymphokine-activated killer cell precursors. J. Immunol. 141:690-698.

14. Clarke, M. F., E. Westin, D. Schmidt, S. F. Josephs, L. Ratner, F. WongStaal, R. C. Gallo, and M. S. Reitz Jr. 1984. Transformation of NIH3T3 cells by a humanc-sis cDNA clone. Nature (Lond.). 308:464-467.

15. Kaneda, Y., K. Iwai, and T. Uchida. 1989. Increased expression of DNA cointroduced with nuclear protein in adult rat liver. Science (Wash. DC). 243:375-378.

16. Kato, K., Y. Kaneda, M. Sakurai, M. Nakanishi, and Y. Okada. 1991. Direct injection of Hepatitis B virus DNA into liver induced Hepatitis in adult rats. J. Biol. Chem. 266:22071-22074.

17. Raij, L., S. Azar, and W. Keane. 1984. Mesangial immune injury, hypertension, and progressive glomerular damage in Dahl rats. Kidney Int. 26:137143.

18. Border, W. A., S. Okuda, L. R. Languino, and E. Ruoslahti. 1990. Trans- forming growth factor- $\beta$ regulates production of proteoglycans by mesangial cells Kidney Int. 37:689-695.

19. Border, W. A., and E. Ruoslahti. 1990. Transforming growth factor- $\beta 1$ induces extracellular matrix formation in glomerulonephritis. Cell Differ. Dev. 32:425-432.

20. Mene, P., M. S. Simonson, and M. J. Dunn. 1989. Physiology of the Mesangial cell. Physiol. Rev. 69:1347-1424.

21. Yoshioka, K., T. Takemura, M. Tohda, N. Akano, H. Miyamoto, A Ooshita, and S. Maki. 1989. Glomerular localization of type III collagen in human kidney disease. Kidney Int. 35:1203-1211.

22. Shultz, P. J., P. E. DiCorleto, B. J. Silver, and H. E. Abboud. 1988 Mesangial cells express PDGF mRNAs and proliferate in response to PDGF. Am. J. Physiol. 255:F674-F684.

23. Eriksson, A., M. Nister, P. Leveen, B. Westermark, C. H. Heldin, and L. Clesson-Welsh. 1991. Induction of Platelet-derived growth factor $\alpha$-and $\beta$-receptor mRNA and protein by platelet-derived growth factor BB. J. Biol. Chem. 266:21138-21144. 